\title{
Sensitivity of western north Pacific summertime tropical synoptic- scale disturbances to extratropical forcing - A regional climate model study
}

\section{Ying Lung Liu}

Earth System Science Programme, the Chinese University of Hong Kong

Chi-Yung Tam ( $\sim$ Francis.Tam@cuhk.edu.hk)

Earth System Science Programme, the Chinese University of Hong Kong https://orcid.org/0000-00025462-6880

\section{Andie Yee Man Au-Yeung}

Earth System Science Programme, the Chinese University of Hong Kong

\section{Research Article}

Keywords: tropical synoptic-scale disturbances, extratropical forcing, regional model

Posted Date: June 28th, 2021

DOl: https://doi.org/10.21203/rs.3.rs-659330/v1

License: (c) (1) This work is licensed under a Creative Commons Attribution 4.0 International License. Read Full License

Version of Record: A version of this preprint was published at Journal of the Meteorological Society of Japan. Ser. II on January 1st, 2022. See the published version at https://doi.org/10.2151/jmsj.2022-008. 


\section{Sensitivity of western north Pacific summertime tropical synoptic-}

scale disturbances to extratropical forcing - A regional climate model

$$
\text { study }
$$

Ying Lung Liu, Chi-Yung Tam and Andie Yee Man Au-Yeung

Earth System Science Programme, the Chinese University of Hong Kong, Hong Kong, China

To be submitted to Journal of Meteorological Society of Japan

First submitted in January 2021

Revised in June 2021

*Corresponding author address: Dr. Chi-Yung Francis Tam, Earth System Science Programme,

Faculty of Science, The Chinese University of Hong Kong, Hong Kong, China. E-mail: 


\section{Abstract}

The role of extratropical forcing on the summertime tropical synoptic-scale disturbances (TSDs) in the western north Pacific has been investigated, by conducting parallel integrations of the Regional Climate Model (RegCM). The suite of experiments consists of a control run (CTRL) with European Centre for Medium Range Forecasts (ECMWF) Reanalysis data as boundary conditions, and an experimental run (EXPT) with the same setting, except that signals with zonal wavenumber $>6$ were suppressed at the northern boundary (located at $42^{\circ} \mathrm{N}$ ) of the model domain. Comparison between CTRL and EXPT showed that, without extratropical forcing, there is weaker TSD activity in the June-to-August season, with reduced precipitation over the TSD pathway. Associated with suppressed TSD, southeastward-directed wave activity is also reduced, leading to less active mixed Rossby gravity (MRG) waves in the equatorial western Pacific area. Further analysis revealed that extratropical forcing and associated circulation changes can modulate the TSD wavetrain and its coherence structure, in relation to low-level vorticity in far western north Pacific. In CTRL, west of about $140^{\circ} \mathrm{E}$, TSD-related circulation tends to be stronger; in EXPT, vorticity signals and vertical motions are found to be slightly more coherent in the more eastern portion of the TSD wavetrain. The latter enhanced coherency of TSD east of $140^{\circ} \mathrm{E}$, from the EXPT simulations, might be due to changes in wave activity transport channelled by 
modulated upper-level mid-latitude westerlies in EXPT. Energetics indicate that changes in low-level background circulation itself can also influence TSD characteristics. Our results serve to quantify how extratropical forcing and related general circulation features influence western north Pacific summertime TSD activities. Implications on understanding the initiation of TSD, as well as their variability on longer time scales, are discussed. 


\section{Introduction}

2 Summertime tropical synoptic-scale disturbances (TSDs) and their impacts on the tropical weather have interested meteorologists and atmospheric scientists for a long

4 time (Yanai and Maruyama 1966; Nitta 1970; Wallace 1971; Nitta and Takayabu 1985;

5 Dickinson and Molinari 2002). With periods of $\sim 3$ to 8 days and wavelengths of $\sim 3000$

$6 \mathrm{~km}, \mathrm{TSD}$ are active over various tropical oceanic areas, including the off-equatorial

7 western north Pacific (Lau and Lau 1990). TSD in this region originate at about $160^{\circ} \mathrm{E}$

8 along the equator and propagate westward, reaching the Asian Continent (Nitta and

9 Takayabu 1985; Dickinson and Molinari 2002). These systems are associated with low-

10 level wave troughs (i.e. vorticity maxima), which in turn are collocated with warm cores

11 in the mid troposphere at about $500 \mathrm{hPa}$. Cold anomaly is found above and below the

12 warm perturbation, implying a sandwiched vertical temperature structure of TSD

13 (Wallace and Chang 1969; Reed and Recker 1971; Lau and Lau 1990; Tam and Li 2006;

14 Serra et al. 2008). Mechanisms for TSD development include local baroclinic and

15 barotropic instability (Chang et al. 1970; Burpee 1972; Lau and Lau 1992; Maloney

16 and Hartmann 2001; Wu et al. 2014; Feng et al. 2014), while these disturbances are also

17 closely related to other equatorial waves, for instance mixed Rossby-gravity (MRG)

18 waves (Takayabu and Nitta 1993; Liebmann et al. 1990; Dunkerton and Baldwin 1995;

19 Chen and Tam 2012). Apart from temperature anomalies, the wave troughs are also 
associated with strong convection and low-level convergence (Reed and Recker 1971;

21 Lau and Lau 1990: Serra et al. 2008).

It is also well recognized that summertime TSDs are related to genesis and

23 development of tropical cyclones (TC) (Maloney and Hartmann 2001; Schreck et al.

24 2012; Feng et al. 2014). In particular, under favorable conditions, TCs can be formed

25 due to TSD-related intense diabatic heating (Frank and Roundy 2006) and strong low-

26 level convergence (Heta 1991). TSD is responsible for about $10-20 \%$ of TC genesis

27 cases in the western north Pacific, and the number even reaches $\sim 60 \%$ in north Atlantic

28 (Chen et al. 2008). The difference in the proportion of TSD-induced TC formation

29 between two ocean basins is due to the presence of the monsoon gyre, to which about

$3070 \%$ of TC formation in the western north Pacific region is related (Chen et al. 2008).

31 Apart from TCs, TSD can interact with/influenced by circulation patterns on a variety

32 of timescales, such as the Madden-Julian Oscillation (MJO) (Madden and Julian 1971;

33 Maloney and Hartmann 2001; Cho et al. 2004) and El Niño-Southern Oscillation

34 (ENSO) (Wu et al. 2014). TSD itself can also contribute to about $10 \%$ of the variability

35 of western tropical Pacific summertime precipitation (Lubis and Jacobi 2015). A better

36 understanding of factors affecting TSD is hence essential for improving tropical

37 weather forecasts, seasonal climate predictions as well as climate projections over the

38 tropical to subtropical area. 
wave activity from extratropical regions to the tropics. In particular, intrusion of upper-

41 level potential vorticity from the mid latitudes can lead to the formation of vorticity

42 perturbations over the tropics, which later develops into TSD through wave energy

43 dispersion. Later climatological analyses (Fukutomi and Yasunari 2014; Archambault

44 et al. 2015) and single-case studies (Molinari and Vollaro 2012) also point out that the

45 extratropical westerly flow can play a role in the formation and the strengthening of

46 tropical easterly waves. Extratropical forcing can therefore be an important source of

47 TSD variability. In this study, we revisit the problem by assessing the contribution of

extratropical wave activity to TSD over the western north Pacific, based on regional atmospheric model experiments. By comparing results from parallel integrations with and without mid-latitude synoptic-scale waves in the model environment, the influence

51 of extratropical forcing on TSD, including its associated tropical circulation impacts,

52 can be inferred. Note that, hitherto, very few studies have explored such tropical-

53 extratropical linkage using numerical models. The rest of this paper is organized as

54 follows. Model setup and experimental design are outlined in Section 2. Section 3 gives

55 the impacts of extratropical wave activity on the variability and structure of TSD, as

56 well as the summertime tropical circulation over the western Pacific. Discussion and 57 conclusion can be found in Section 4. 


\section{Model experiments and data used}

To test the sensitivity of TDS to extratropical forcing, numerical experiments were

carried out using the Regional Climate Model system 3 (RegCM3), which is a

Theoretical Physics (ICTP). It was run at the horizontal resolution of $60 \times 60 \mathrm{~km}$, with

6418 sigma levels, within the domain of $13^{\circ} \mathrm{S}-42^{\circ} \mathrm{N}$ and $80^{\circ} \mathrm{E}-160^{\circ} \mathrm{W}$ (see Fig. 1).

65 Model parameterization schemes used included the modified Emanuel Scheme for cumulus convection (Emmanuel 1991, Chow et al. 2006), Pal scheme (Pal et al. 2000) for large-scale precipitation, BATS scheme for land-surface processes, Holtslag scheme (Holtslag et al. 1990) for planetary-boundary-layer processes, and NCAR CCM3 radiative scheme (Kiehl et al. 1998).

71 September period. Six-hourly data from the European Centre for Medium Range

72 Forecasts (ECMWF) Reanalysis (ERA-40; Uppala et al. 2005), as well as the

73 climatological monthly mean National Oceanic and Atmospheric Administration

74 (NOAA) Optimum Interpolation Sea Surface Temperature (OISST; Reynolds et al.

75 2002), were used as initial and lateral boundary conditions. Reanalysis data from seven

76 selected years, namely 1983, 1984, 1986, 1990, 1992, 1993, and 2001 were chosen. 
77 Note that these years were not major El Niño nor La Niña events; they were chosen so

78 as to avoid seasons during which there were prominent east-west shifts of synoptic-

79 scale activities due to major ENSO events (Sobel and Maloney, 2001). Based on these

80 seven years, six-hourly climatology of dynamic and thermodynamic variables (i.e.,

81 wind, temperature, and humidity), at all vertical levels, was first obtained, and then

82 filtered to retain signals with zonal horizontal scales equivalent or larger than those for

83 wavenumber 6 (i.e. zonal wavenumber $|\mathrm{k}|$ within 0 to 6 ). The spatially smoothed data

84 were used as lateral boundary conditions for model integrations. At the northern

85 boundary, transients (i.e. deviations from the seasonal mean) with $|\mathrm{k}|>6$, archived from

86 each prescribed year, were superimposed onto the derived climatology, and the model

87 was integrated for each of these years. In the control experiment (hereinafter referred

88 to as CTRL), transients were set to their original amplitudes; in the other experiment

89 (referred to as EXPT), transients with only $10 \%$ of their original amplitudes were then

90 superimposed onto the climatology (see Tab. 1). For the eastern, western and southern

91 boundary in both experiments, no transient signals were imposed. As a result, the only

92 difference between the two experiments is the magnitude of $|\mathrm{k}|>6$ perturbations at the

93 northern boundary. For each April-to-September period, five ensemble integrations

94 were conducted, with the $\mathrm{n}^{\text {th }}$-ensemble member initiated by treating the $\mathrm{n}^{\text {th }}$ day in April

95 as the initial condition for the $1^{\text {st }}$ of April. By comparing the difference between EXPT 
and CTRL, we can evaluate how extratropical synoptic-scale forcing from the northern

97 boundary of the domain affects the regional climate, focusing on the behavior of TSD.

98 In this study, only data from June to August (JJA) were used for all analyses. To depict wave activities and forcing with extratropical origins, eddy heat transport at $850 \mathrm{hPa}$ and also $200 \mathrm{hPa}$ E-vectors from CTRL and EXPT were computed. Following

101 Trenberth (1986), the E-vectors are defined as $\overrightarrow{\mathrm{E}}=\left[\overline{\frac{\mathrm{v}^{\prime 2}-u^{\prime 2}}{2}},-\overline{u^{\prime} v^{\prime}}\right]$, with prime 102 denoting 3-to-8 day band-pass filtered values, and overbar seasonal and ensemble 103 averaging. Results for heat transport $\overline{T^{*} v^{*}}$, with asterisk denoting deviations from the 104 seasonal mean, and E-vectors from the two experiments are given in Fig. 2. It can be 105 clearly seen that there are strong southeastward directed $200 \mathrm{hPa}$ E-vectors at the 106 northern boundary in CTRL, but not in EXPT (see Fig. 2a). This indicates southward 107 wave energy dispersion from the north in CTRL only, consistent with the experimental 108 setups. The $850 \mathrm{hPa}$ northward heat transport is also stronger in CTRL near the northern 109 boundary, especially over the continental area (see Fig. 2b). As expected, a stronger 110 presence of mid-latitude synoptic-scale waves in CTRL serve to transport more heat to 111 the north in the model environment. Overall, the above confirms that upper-level 112 extratropical forcing from the northern boundary, in relation to mid-latitude synoptic113 scale disturbances, is strongly suppressed in EXPT in comparison to CTRL owing to 114 our experimental design. 


\section{Results}

To understand how synoptic-scale forcing might influence the mean circulation in

117 the western north Pacific region, the background $850 \mathrm{hPa}$ wind, precipitation from of

118 the CTRL and EXPT, as well as their difference, are given in Figs. 3a, 3c, 3e. For CTRL,

119 there is a stronger easterly wind branch over $20-30^{\circ} \mathrm{N}, 120-180^{\circ} \mathrm{E}$, and a stronger

120 northerly branch over the South China Sea. There is more heat transported to the north

121 in CTRL at about $30^{\circ} \mathrm{N}$ at $850 \mathrm{hPa}$ (see Fig. 2 b). The $850 \mathrm{hPa}$ mean temperature on the

122 continent and that over the northern part of the domain is also lower in CTRL (Fig. 2a),

123 which makes the meridional and land-sea temperature (pressure) gradient more

124 negative (positive) in the low levels. This results in low-level wind field changes due

125 to the differences in pressure gradient between CTRL and EXPT. Enhanced

126 precipitation by about $2-4 \mathrm{~mm} /$ day is found within $0-20^{\circ} \mathrm{N}, 100-160^{\circ} \mathrm{E}$ in CTRL.

127 It is worth noting that enhanced precipitation is collocated with typical pathways of

128 TSD. To identified signals of TSD, bandpass filtered $850 \mathrm{hPa}$ vorticity was computed

129 (Lau and Lau 1990). Figs. 3b, 3d, 3f show the variance of the 3-to-8 day filtered low-

130 level vorticity. For CTRL, it can be seen that the vorticity variance is generally larger

131 over $5-25^{\circ} \mathrm{N}, 100-150^{\circ} \mathrm{E}$, indicating stronger synoptic-scale wave activities. This

132 supports the notion that extratropical forcing plays a role in modulating western north

133 Pacific summertime synoptic-scale disturbances. Note that the seasonal mean 
134 precipitation is also enhanced in the same area with enhanced wave activities in CTRL,

135 consistent with the fact that these systems are important in bringing rainfall in region 136 (see Fig. 3e). E-vectors is also used to examine the $850 \mathrm{hPa} 3$-to-8-day wave activity and its

138 related Rossby wave energy dispersion (see Fig. 4). Both CTRL and EXPT give

139 southward and southeastward pointing E-vectors over the region of $5-25^{\circ} \mathrm{N}, 110-$

$140150^{\circ} \mathrm{E}$, where large $850 \mathrm{hPa}$ vorticity variance is found (see Fig. 3). In both experiments,

141 E-vectors are directed to the south to southeast in this area, consistent with the NE-SW

142 tilted structure of the synoptic-scale eddies (Lau and Lau 1990). Note that the

143 magnitude of E-vectors is about $30 \%$ stronger in CTRL, especially for the zonal

144 (eastward) component. This clearly indicates that there are stronger wave-like

145 disturbances in the low levels in CTRL compared with EXPT. Indeed, the difference in

146 E-vectors between the two experiments (see Fig. 3c) suggests that in CTRL, there is

147 stronger southward Rossby wave energy dispersion towards more tropical latitudes.

148 Such a difference can impact on equatorial wave activities over the western Pacific

149 sector, as will be subsequently shown. On the other hand, it is noteworthy that synoptic-

150 scale disturbances are not entirely suppressed in EXPT; in terms of their variance, the 151 suppression is only about $20-30 \%$, despite of the fact that extratropical waves have only $15210 \%$ of their original magnitude (hence $\sim 1 \%$ of variance). This suggests that 
153 summertime tropical synoptic-scale disturbances in western north Pacific can exist, 154 regardless of presence of extratropical forcing from the north.

155 Chen and Tam (2012) reported a mechanism by which TSD can excite MRG waves.

156 To depict activities of equatorial waves, the wavenumber-frequency spectra (Wheeler 157 and Kiladis 1999; Au-Yeung and Tam 2018) of the symmetric component of the 850hPa 158 meridional wind, averaged over $13^{\circ} \mathrm{S}-13^{\circ} \mathrm{N}$, were plotted in Fig. 5. Westward 159 propagating MRG signals in CTRL were found to be significantly stronger than those 160 in EXPT by more than 25\% (about 0.1 in the logarithm plot), implying stronger MRG 161 waves over the equatorial western Pacific in CTRL. This is also in accordance with 162 Dunkerton and Baldwin (1995), who reported transformation of MRG waves to TSD 163 based on observations. Overall, more active TSD and associated MRG waves in the 164 tropical western Pacific are seen in CTRL compared to EXPT, and this is solely due to 165 stronger forcing from extratropical locations in the experimental design. Here we further extract the wave-like signals associated with the synoptic-scale 167 disturbances, using the results from empirical orthogonal function (EOF) analyses 168 based on the bandpass filtered westward propagating $850 \mathrm{hPa}$ vorticity signals over $0-$ $16930^{\circ} \mathrm{N}, 100-160^{\circ} \mathrm{E}$ (see section 2). Fig. 6 shows the standardized spatial pattern of the 170 first and the second leading EOFs, based on data from all ensemble members from both

171 CTRL and EXPT. It can be seen that the structures of all EOFs are wave-like, consistent 
172 with the waveform of TSD reported in previous studies (e.g. Lau and Lau 1990; Reed

173 and Recker 1971). The fraction of domain-integrated variance explained by two leading

174 EOFs are similar (about 10\%), and two patterns are in quadrature in space. These two

175 leading EOFs, together with their PC time series, thus represent westward propagating

176 wave signals in the low-level vorticity. It can be seen that wave trains in both CTRL

177 and EXPT have similar structure and wavelength. They both have the strongest

178 amplitudes within $110-140^{\circ} \mathrm{E}$ and a NE-SW tilted structure west of $150^{\circ} \mathrm{E}$. The wave

179 starts to exhibit the NE-SW tilted structure in a more western location in CTRL than

180 that in EXPT. The less tilted structure of eddies in CTRL over $120-140^{\circ} \mathrm{E}$ may increase

181 the zonal propagation of wave activity and further affect wave energetics (Lau and Lau

182 1992; Trenberth 1986).

183 To analyze the difference in the strength of waves between CTRL and EXPT, time-

184 series of the combined magnitude of the two leading principal components (PC) are

185 computed. The combined magnitude at time $\mathrm{t}$ (= day from June 1$)$ is calculated by first

186 computing $y(t)=\sqrt{P C_{1}(t)^{2}+P C_{2}(t)^{2}}$, where $P C_{1}$ and $P C_{2}$ are the magnitude of

187 the two leading EOFs, for each season and each ensemble member. Finally, for each

188 calendar day the combined magnitude is found by averaging $y(t)$ over all ensemble

189 members and seasons. Results for the two experiments are shown in Fig. 7. It can be

190 seen that during most of the days within the JJA season, CTRL gives stronger 
191 disturbances in this region than EXPT, with a difference reaching about $20 \%$. This is

192 also consistent with the previous result that MRG activities are about $25 \%$ stronger in

193 CTRL (see Fig. 5). This indicates that extratropical forcing contributes to the formation

194 and hence part of the variability of TSD, although the forcing is not a necessary

195 condition for the waves to exist.

To obtain TSD-related circulation patterns, EOF reconstruction and regression

technique are used. In particular, the two abovementioned leading EOFs for the $850 \mathrm{hPa}$

vorticity were first used to reconstruct the vorticity timeseries at the reference point of

$15^{\circ} \mathrm{N}, 120^{\circ} \mathrm{E}$, which is a location with strong signals of TSD in both CTRL and EXPT

(see Figs. 3 and 6). To obtain TSD-related circulation maps for a particular field, the

201 following linear regression method is used:

$$
\phi_{r e g}(x, y)=\overline{[\phi(t, x, y)-\bar{\phi}(x, y)] \times \frac{\left[\hat{\zeta}\left(t, 120^{\circ} \mathrm{E}, 15^{\circ} \mathrm{N}\right)\right]}{\sigma_{\widehat{\zeta}}}} \approx r(\phi, \hat{\zeta}) \times \sigma_{\phi}(x, y),
$$

203 where $\phi$ is the field of interest, $\hat{\zeta}$ is the EOF-filtered $850 \mathrm{hPa}$ vorticity, $\sigma$ is its 204 temporal standard deviation, $r$ is the correlation, bar denotes the time average, $x$ and $205 y$ denote the longitude and latitude of the datapoint. Fig. 8 gives the regression maps 206 for $850 \mathrm{hPa}$ vorticity and precipitation onto the $15^{\circ} \mathrm{N}, 120^{\circ} \mathrm{E}$ values of EOF-filtered 207 vorticity. The structure of the regressed waves is consistent with spatial patterns of the 208 first two leading EOFs shown in Fig. 6 for both CTRL and EXPT, which suggests that 
209 the regression method is able extract the targeted signals. Values of both regressed

$210850 \mathrm{hPa}$ vorticity and precipitation are larger in CTRL than EXPT, consistent with Fig.

211 7, indicating that TSD is stronger in the low levels in CTRL due to the presence of 212 extratropical forcing.

214 in order to the vertical structure of TSD from the model experiments. Fig. 9. Gives the

215 vertical cross-sections of the regressed vorticity and temperature along the TSD

216 wavetrain (see black solid lines in Fig.8). Prominent vorticity perturbations with deep

217 vertical extent can be seen, with westward tilted structure (see Lau and Lau 1990). West

218 of about $150^{\circ} \mathrm{E}$, the temperature field is strongest in the $500-400 \mathrm{hPa}$ layer, with

219 anomalies almost in phase with those of the vorticity. At the 900 to $850 \mathrm{hPa}$ levels,

220 however, anomalous positive (negative) vorticity tends to be more collocated with cold

221 (warm) perturbations. These circulation features, seen in both model experiments, are

222 consistent with the observed structure of TSD (Tam and Li 2006; Au-Yeung and Tam

223 2018). The differences between the CTRL and EXPT vertical cross sections are also

224 computed (see Fig. 9c). The middle-level temperature and the low-level vorticity

225 perturbations in CTRL are significantly larger than those in EXPT west of about $140^{\circ} \mathrm{E}$.

226 Again, this points to the fact that extratropical forcing leads to stronger wave amplitudes

227 in the more western part of the TSD wavetrain. However, it is noteworthy that signals 
228 are found to be stronger in EXPT east of $140^{\circ} \mathrm{E}$ from the surface to about $500 \mathrm{hPa}$. In

229 this region over the more eastern part of the wavetrain, stronger vortices and 230 accompanying temperature anomalies can be seen in EXPT (see box region in Fig. 9c).

231 It suggests that wave activity in this domain is more influenced by disturbances 232 generated locally or east of $140^{\circ} \mathrm{E}$. (Note that, above the $250 \mathrm{hPa}$ level, TSD from CTRL 233 still appears to be more active than EXPT; further inspection of temperature and 234 vorticity placement indicates stronger downward wave activity flux (Tam and Li 2006) 235 in CTRL, as expected from stronger extratropical forcing in this experiment.)

236 We have also computed the anomalous pressure velocity $\left(\omega^{\prime}\right)$ and its correlation

237 with $\hat{\zeta}$, at different levels from CTRL and EXPT, as well as the difference in $\omega^{\prime}$ 238 between the two experiments (Fig. 10). Compared with Fig. 9, over the western part of 239 the wavetrain, rising motion (subsidence) is seen to coincide with positive (negative) 240 vorticity at about $500 \mathrm{hPa}$. East of $\sim 140^{\circ} \mathrm{E}$, strongest vertical motion is located east of 241 the anomalous vortices, but slightly west of the temperature signals. Consistent with 242 Fig. 9, anomalous risking/sinking west of $140^{\circ} \mathrm{E}$ have larger amplitudes in CTRL 243 compared to EXTP, while stronger and more coherent vertical motion is found in EXPT 244 at more eastern locations. The latter is clearly related to stronger coherence between $\omega^{\prime}$ 245 and $\hat{\zeta}$ in that part of the TSD wavetrain. To summarize, although TSD becomes 
246 stronger overall in CTRL due to extratropical forcing, within $140^{\circ}$ to $180^{\circ} \mathrm{E}$ the

247 wavetrain is slightly stronger and with more coherent circulation structure in EXPT.

248 Fig. 11 gives CTRL minus EXPT JJA mean 200hPa geopotential height and

249 circulation, with zero-zonal wind contours included to indicate the presence of the

250 tropical upper tropospheric trough (TUTT). The upper-level Asian high is stronger in

251 EXPT under a warmer troposphere, due to less northward eddy temperature transport

252 at low levels (see Fig. 2). As a result, there is stronger zonal flow north of $20^{\circ} \mathrm{N}$ in

253 EXPT. Enhanced westerlies and stronger stationary wave features might channel more

254 wave activity and trigger TSD at the TUTT locations (e.g., Sadler 1967; Tam and Li

255 2006; Feng et al. 2020; Wang et al. 2020). In addition, the TUTT axis is located more

256 to the southeastern in EXPT (not shown, but see Fig. 11). This and more active TUTT

257 cells under stronger upper-level northeasterlies might also enhance low level TSD in

258 the western north Pacific (Wen et al. 2018; Guo and Ge 2018). Additional analysis based

259 on E-vectors associated with TSD formation is consistent with this interpretation

260 (figures not shown).

\section{Discussions and Conclusion}

262 The sensitivity of western north Pacific summertime TSD to extratropical forcing

263 has been examined, by comparing a regional climate model control run in boreal 
264 summer, with an experimental run having the same setting except with suppressed

265 synoptic-scale variability at its northern boundary. Consistent with the above model

266 design, in JJA southward directed upper-level E-vectors and low-level northward heat

267 transports north of about $25^{\circ} \mathrm{N}$ were found to be reduced in the experimental run,

268 compared to the control run. This means that in the former, mid-latitude synoptic-scale

269 disturbances are indeed suppressed, with implications on the regional circulation within

270 the model environment. Further comparison between the two experiments revealed that,

271 in the presence of extratropical forcing, there is stronger TSD activity over the western

272 Pacific between 10 to $25^{\circ} \mathrm{N}$. Along the propagation path of TSD, precipitation is also

273 intensified. Also, stronger southeastward low-level Rossby wave energy dispersion

274 associated with TSD was found, leading to more active MRG waves at $850 \mathrm{hPa}$ over the

275 equatorial western Pacific sector. Thus, via the triggering of TSD, forcing related to

276 extratropical synoptic-scale activity can lead to stronger tropical disturbance/MRG

277 waves, as well as their associated rainfall in summertime western north Pacific.

278 The TSD-related anomalous circulation from the two experiments was further

279 examined, by regressing various meteorological variables onto the standardized EOF-

280 filtered low-level vorticity at $15^{\circ} \mathrm{N}, 120^{\circ} \mathrm{E}$. Compared with the experimental run, TSD

281 wavetrain from the control run tends to be stronger west of $140^{\circ} \mathrm{E}$, with stronger

282 vortices and more vigorous anomalous vertical motion. However, in the eastern portion 
283 (140 to $\left.\sim 180^{\circ} \mathrm{E}\right)$ of the TSD wavetrain, relatively stronger and more coherent wave

284 signals exist in the experimental run. Further inspection showed that, in the latter run,

285 the upper-level Asian high is stronger due to less northward eddy heat flux; it is possible

286 that the strengthened anticyclone might channel more mid latitude wave activity to

287 TUTT, which excites more TSD. Diagnostics based on E-vectors associated with TSD

288 formation support this view.

289 Apart from the modulated upper-level flow, changes in the low-level mean

290 circulation might also affect TSD characteristics. Fig. 12 shows the differences between

291 TSD-related $850 \mathrm{hPa}$ barotropic energy conversion rate in CTRL and EXPT. The

292 barotropic energy conversion rate $(B T)$ is given by:

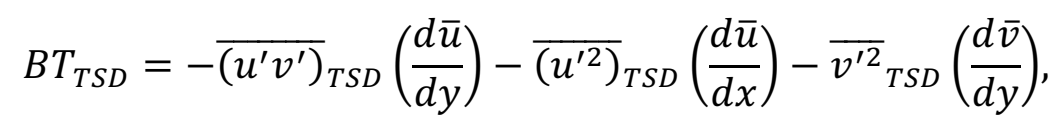

294 where subscript TSD denotes variables regressed onto $\hat{\zeta}$ for lag -8 to +8 . Written this 295 way, contributions from background wind change wind $\left(B T_{B G}\right)$ and changes in eddies $296\left(B T_{E D}\right)$ can be separated:

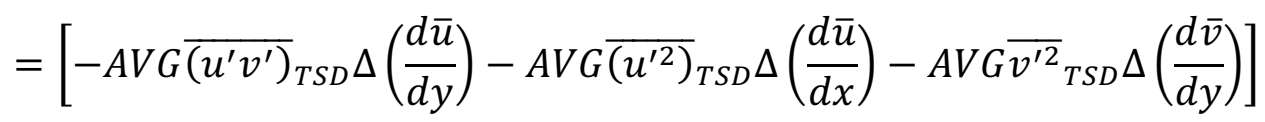

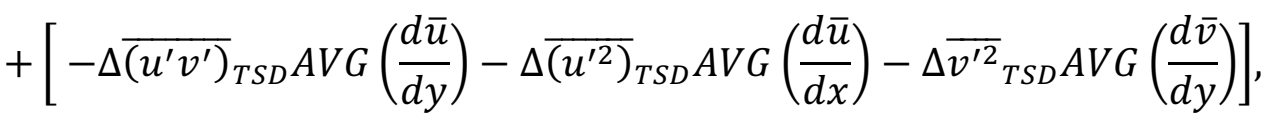


301 respectively. It can be seen that barotropic energy conversion is higher in CTRL over $30210-20^{\circ} \mathrm{N}, 110-140^{\circ} \mathrm{E}$ (Fig. 12a), consistent with stronger eddies in this run (see Figs. 8, 303 9, and 10). $B T_{B G}\left(B T_{E D}\right)$ is larger (smaller) in latitudes $10-15^{\circ} \mathrm{N}$ but smaller (larger) 304 in $15-20^{\circ} \mathrm{N}$ in CTRL. In fact, $B T_{B G}$ and $B T_{E D}$ are comparable in magnitudes but with 305 most positive and negative signals found in locations complementary to each other (see 306 Figs. 12b and 12c). Therefore, both effects are needed to fully account for BT. Further 307 breakdown of $B T_{B G}$ shows that changes in $\frac{d \bar{u}}{d y}$ and $\frac{d \bar{v}}{d y}\left(\frac{d \bar{u}}{d x}\right)$ enhance (suppress) TSD 308 west of $140^{\circ} \mathrm{E}$ in CTRL (not shown), consistent with the changes in JJA mean $850 \mathrm{hPa}$ 309 circulation (Fig. 3e). This study helps to quantify the role of extratropical wave activity in determining 311 TSD variability. In terms of low-level vorticity (MRG-related v-wind) anomalies over 312 the far western north (equatorial) Pacific, suppression of extratropical forcing leads to $313 \sim 20-25 \%$ reduction of their variance in the model environment. Though not the major 314 contributor to the climatological mean activity, equatorward wave energy dispersion 315 due to extratropical systems might still influence TSD amplitudes from year to year. 316 This type of forcing can be sensitive, for instance, to the structure and location of the 317 subtropical jet. More studies need to be carried out, in order to better understand how 318 mid-latitude forcing influences the sub-seasonal to seasonal TSD activity or in fact 
319 other related tropical systems such as tropical cyclones, and how such forcing might

320 depend on the background circulation.

321 Finally, it is worth mentioning that the regional climate model can well capture the

322 circulation structure of TSD, including their connection with to low-level MRG waves

323 through equatorward energy dispersion. It remains possible that other equatorial wave

324 types (for instance $\mathrm{n}=1$ equatorial Rossby waves, which are also important for TC

325 genesis) might also be affected by mid-latitude forcing. Further observational and

326 modelling studies will be conducted in this direction. Numerical experiments, similar

327 to those in this study, can be designed for examining the sensitivity of these equatorial

328 waves to various components of the extratropical circulation. This can be a useful

329 method for studying this aspect of the tropical-extratropical linkage in the atmospheric

330 general circulation. 


\section{Acknowledgements}

We thank Swadhin Behara and Bunmei Taguchi for discussions. RegCM3 simulations were carried out by Kit Ying Fung while she was at the City University of Hong Kong. This work is based on the undergraduate capstone project of Y. L. Liu at the Earth System Science Programme of CUHK. 


\section{References}

Archambault, H. M., Keyser, D., Bosart, L. F., Davis, C. A., \& Cordeira, J. M. (2015). A composite perspective of the extratropical flow response to recurving western North Pacific tropical cyclones. Monthly Weather Review, 143(4), 1122-1141.

Au-Yeung, A. Y. M., \& C.-Y. Tam, (2018). Dispersion characteristics and circulation associated with boreal summer westward travelling mixed-Rossby gravity wave-like disturbances, J. Atmos. Sci., 75 (2): 513-533.

Burpee, R. W. (1972). The origin and structure of easterly waves in the lower troposphere of North Africa. Journal of the Atmospheric Sciences, 29(1), 77-90.

Chang, C. P., Morris, V. F., \& Wallace, J. M. (1970). A statistical study of easterly waves in the western Pacific: July-December 1964. Journal of the Atmospheric Sciences, 27(2), 195-201.

Chen, T. C., Wang, S. Y., Yen, M. C., \& Clark, A. J. (2008). Are tropical cyclones less effectively formed by easterly waves in the western north Pacific than in the North Atlantic?. Monthly Weather Review, 136(11), 4527-4540. 
Chen, G., \& Tam, C. Y. (2012). A new perspective on the excitation of lowtropospheric mixed Rossby-gravity waves in association with energy dispersion. Journal of the Atmospheric Sciences, 69(4), 1397-1403.

Cho, H. K., Bowman, K. P., \& North, G. R. (2004). Equatorial waves including the Madden-Julian oscillation in TRMM rainfall and OLR data. Journal of Climate, 17(22), 4387-4406.

Chow, K. C., Chan, J. C., Pal, J. S., \& Giorgi, F. (2006). Convection suppression criteria applied to the MIT cumulus parameterization scheme for simulating the Asian summer monsoon. Geophysical Research Letters, 33(24).

Dickinson, E., Henderson-Sellers, A., \& Kennedy, J. (1993). Biosphere-atmosphere transfer scheme (BATS) version 1e as coupled to the NCAR community climate model.

Dickinson, M., \& Molinari, J. (2002). Mixed Rossby-gravity waves and western Pacific tropical cyclogenesis. Part I: Synoptic evolution. Journal of the Atmospheric Sciences, 59(14), 2183-2196. 
Dunkerton, T. J., \& Baldwin, M. P. (1995). Observation of 3-6-day meridional wind oscillations over the tropical Pacific, 1973-1992: Horizontal structure and propagation. Journal of the Atmospheric Sciences, 52(10), 1585-1601.

Emanuel, K. A. (1991). A scheme for representing cumulus convection in large-scale models. Journal of the Atmospheric Sciences, 48(21), 2313-2329.

Feng, T., Chen, G. H., Huang, R. H., \& Shen, X. Y. (2014). Large-scale circulation patterns favourable to tropical cyclogenesis over the western north Pacific and associated barotropic energy conversions. International Journal of Climatology, $34(1), 216-227$.

Feng, T., Yang, X. Q., Wu, L., Huang, R., \& Yang, D. (2020). How do the monsoon trough and the tropical upper-tropospheric trough affect synoptic-scale waves: A comparative study. Journal of the Meteorological Society of Japan. Ser. II.

Frank, W. M., \& Roundy, P. E. (2006). The role of tropical waves in tropical cyclogenesis. Monthly Weather Review, 134(9), 2397-2417.

Fukutomi, Y., \& Yasunari, T. (2014). Extratropical forcing of tropical wave disturbances along the Indian Ocean ITCZ. Journal of Geophysical Research: Atmospheres, 119(3), 1154-1171. 
Giorgi, F., Marinucci, M. R., \& Bates, G. T. (1993a). Development of a secondgeneration regional climate model (RegCM2). Part I: Boundary-layer and radiative transfer processes. Monthly Weather Review, 121(10), 2794-2813.

$-, \frac{-}{-}, \frac{1}{-}, \frac{}{2}$ De Canio, G. (1993). Development of a second-generation
regional climate model (RegCM2). Part II: Convective processes and
assimilation of lateral boundary conditions. Monthly Weather Review, 121(10), 2814-2832.

—, Coppola, E., Solmon, F., Mariotti, L., Sylla, M. B., Bi, X., ... \& Turuncoglu, U. U. (2012). RegCM4: model description and preliminary tests over multiple CORDEX domains. Climate Research, 52, 7-29.

Guo, B., \& Ge, X. (2018). Monsoon trough influences on multiple tropical cyclones events in the western North Pacific. Atmospheric Science Letters, 19(9), e851.

Holtslag, A. A. M., De Bruijn, E. I. F., \& Pan, H. L. (1990). A high resolution air mass transformation model for short-range weather forecasting. Monthly Weather Review, 118(8), 1561-1575. 
Kiehl, J. T., Hack, J. J., Bonan, G. B., Boville, B. A., Williamson, D. L., \& Rasch, P. J. (1998). The national center for atmospheric research community climate model: CCM3. Journal of Climate, 11(6), 1131-1149.

Lau, K. H., \& Lau, N. C. (1990). Observed structure and propagation characteristics of tropical summertime synoptic scale disturbances. Monthly Weather Review, $118(9), 1888-1913$.

— \& $\&$ (1992). The energetics and propagation dynamics of tropical summertime synoptic-scale disturbances. Monthly Weather Review, 120(11), 2523-2539.

Liebmann, B., \& Hendon, H. H. (1990). Synoptic-scale disturbances near the equator. Journal of the Atmospheric Sciences, 47(12), 1463-1479.

Lubis, S. W., \& Jacobi, C. (2015). The modulating influence of convectively coupled equatorial waves (CCEWs) on the variability of tropical precipitation. International Journal of Climatology, 35(7), 1465-1483.

Madden, R. A., \& Julian, P. R. (1971). Detection of a 40-50 day oscillation in the zonal wind in the tropical Pacific. Journal of the Atmospheric Sciences, 28(5), 702708. 
Maloney, E. D., \& Hartmann, D. L. (2001). The Madden-Julian oscillation, barotropic dynamics, and North Pacific tropical cyclone formation. Part I: Observations. Journal of the Atmospheric Sciences, 58(17), 2545-2558.

Matsuno, T. (1966). Quasi-geostrophic motions in the equatorial area. Journal of the Meteorological Society of Japan. Ser. II, 44(1), 25-43.

Molinari, J., \& Vollaro, D. (2012). A subtropical cyclonic gyre associated with interactions of the MJO and the midlatitude jet. Monthly weather review, 140(2), 343-357.

Nitta, T., \& Takayabu, Y. (1985). Global analysis of the lower tropospheric disturbances in the tropics during the northern summer of the FGGE year part II: Regional characteristics of the disturbances. Pure and Applied Geophysics, 123(2), 272-292.

(1970). Statistical study of tropospheric wave disturbances in the tropical Pacific region. Journal of the Meteorological Society of Japan. Ser. II, 48(1), 47-60.

Pal, J. S., Small, E. E., \& Eltahir, E. A. (2000). Simulation of regional-scale water and energy budgets: Representation of subgrid cloud and precipitation processes 
within RegCM. Journal of Geophysical Research: Atmospheres, 105(D24), 29579-29594.

, Giorgi, F., Bi, X., Elguindi, N., Solmon, F., Gao, X., ... \& Ashfaq, M. (2007). Regional climate modeling for the developing world: the ICTP RegCM3 and RegCNET. Bulletin of the American Meteorological Society, 88(9), 1395-1410.

Reed, R. J., \& Recker, E. E. (1971). Structure and properties of synoptic-scale wave disturbances in the equatorial western Pacific. Journal of the Atmospheric Sciences, 28(7), 1117-1133.

Reynolds, R. W., Rayner, N. A., Smith, T. M., Stokes, D. C., \& Wang, W. (2002). An improved in situ and satellite SST analysis for climate. Journal of Climate, 15(13), 1609-1625.

Sadler, J. C., (1967). The tropical upper tropospheric trough as a secondary source of typhoons and a primary source of tradewind disturbances. Hawaii Institute of Geophysics Rep. 67-12, 44.

Schreck III, C. J., Molinari, J., \& Aiyyer, A. (2012). A global view of equatorial waves and tropical cyclogenesis. Monthly Weather Review, 140(3), 774-788. 
Serra, Y. L., Kiladis, G. N., \& Cronin, M. F. (2008). Horizontal and vertical structure of easterly waves in the Pacific ITCZ. Journal of the Atmospheric Sciences, 65(4), 1266-1284.

Sobel, A.H., and E.D. Maloney, (2000). Effect of ENSO and the MJO on western north Pacific tropical cyclones. Geophys. Res. Lett., 27, 1739-1742.

Takayabu, Y. N., \& Nitta, T. (1993). 3-5 day-period disturbances coupled with convection over the tropical Pacific Ocean. Journal of the Meteorological Society of Japan. Ser. II, 71(2), 221-246.

Tam, C. Y., \& Li, T. (2006). The origin and dispersion characteristics of the observed tropical summertime synoptic-scale waves over the western Pacific. Monthly Weather Review, 134(6), 1630-1646.

Trenberth, K. E. (1986). An assessment of the impact of transient eddies on the zonal flow during a blocking episode using localized Eliassen-Palm flux diagnostics. Journal of the Atmospheric Sciences, 43(19), 2070-2087.

Uppala, S. M., Kållberg, P. W., Simmons, A. J., Andrae, U., Bechtold, V. D. C., Fiorino, M., ... \& Li, X. (2005). The ERA-40 re-analysis. Quarterly Journal of the Royal 
Meteorological Society: A journal of the atmospheric sciences, applied meteorology and physical oceanography, 131(612), 2961-3012.

Wallace, J. M. (1971). Spectral studies of tropospheric wave disturbances in the tropical western Pacific. Reviews of Geophysics, 9(3), 557-612.

, \& Chang, C. P. (1969). Spectrum analysis of large-scale wave disturbances in the tropical lower troposphere. Journal of the Atmospheric Sciences, 26(5), $1010-1025$.

Wang, Z., Zhang, G., Dunkerton, T. J., \& Jin, F. F. (2020). Summertime stationary waves integrate tropical and extratropical impacts on tropical cyclone activity. Proceedings of the National Academy of Sciences, 117(37), 22720-22726.

Wen, D., Li, Y., Zhang, D. L., Xue, L., \& Wei, N. (2018). A statistical analysis of tropical upper-tropospheric trough cells over the western North Pacific during 2006-15. Journal of Applied Meteorology and Climatology, 57(11), 2469-2483.

Wheeler, M., \& Kiladis, G. N. (1999). Convectively coupled equatorial waves: Analysis of clouds and temperature in the wavenumber-frequency domain. Journal of the Atmospheric Sciences, 56(3), 374-399. 
Wu, L., Wen, Z., Li, T., \& Huang, R. (2014). ENSO-phase dependent TD and MRG wave activity in the western north Pacific. Climate dynamics, 42(5-6), 12171227.

Yanai, M., \& Maruyama, T. (1966). Stratospheric wave disturbances propagating over the equatorial Pacific. Journal of the Meteorological Society of Japan. Ser. II, 44(5), 291-294. 


\section{Figures}

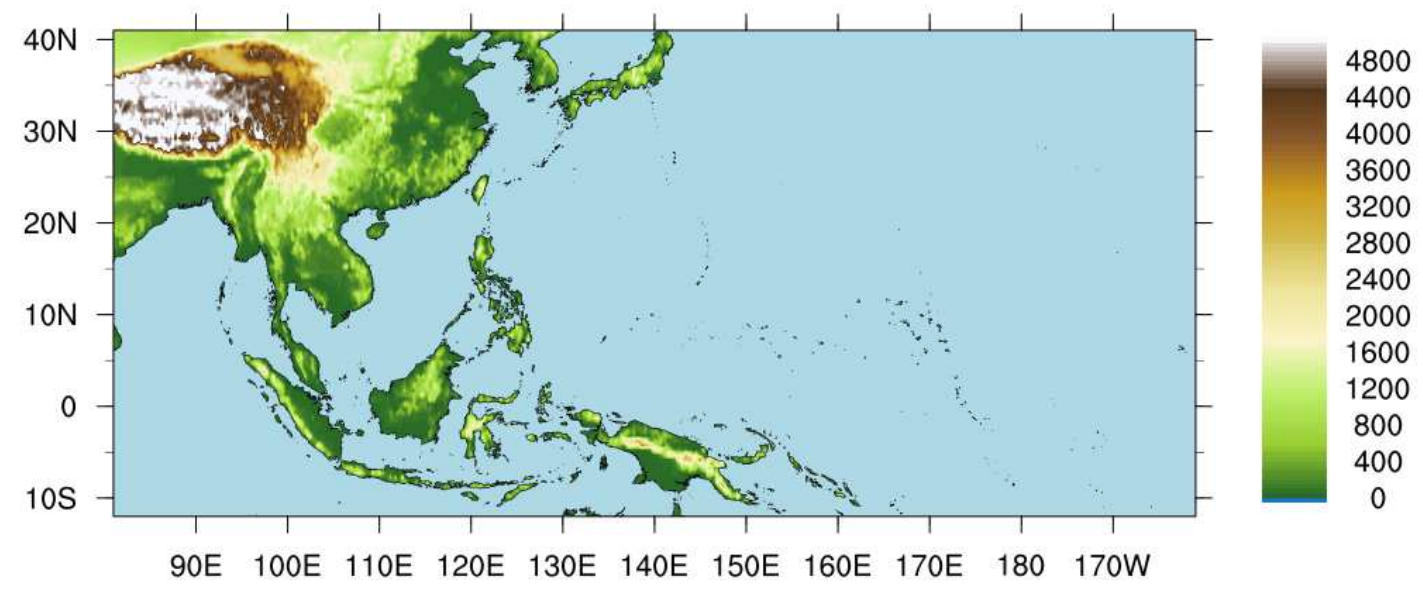

Figure 1. Model domain for RegCM3 simulations $\left(13^{\circ} \mathrm{S}-42^{\circ} \mathrm{N}, 80^{\circ} \mathrm{E}-160^{\circ} \mathrm{W}\right)$ and topography therein (shading; units: m). 

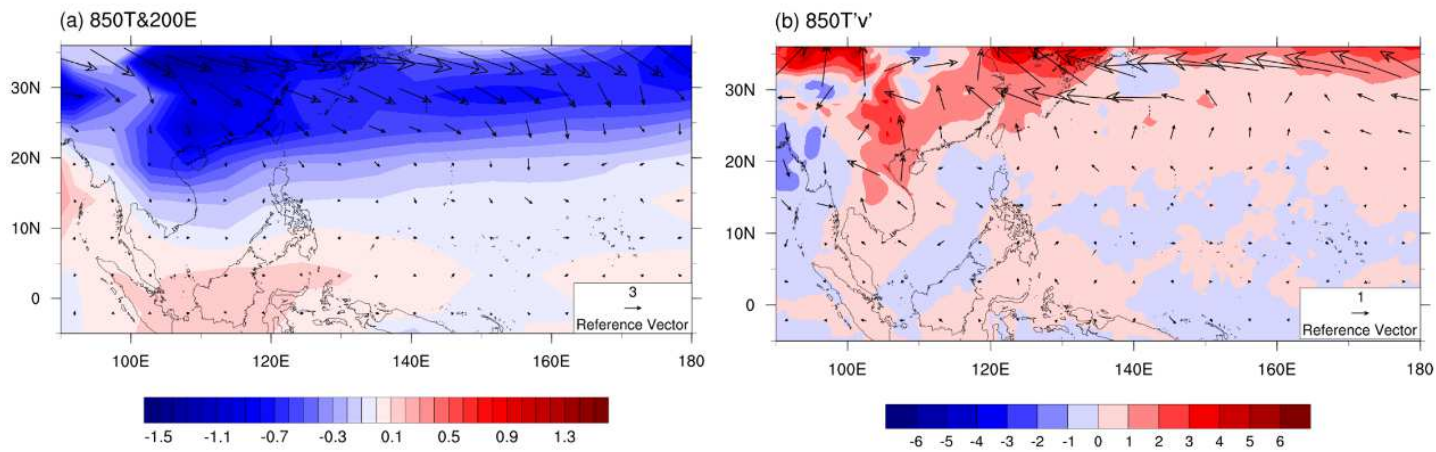

Figure 2. CTRL minus EXPT values of (a) $850 \mathrm{hPa}$ JJA mean temperature (shading; units: K) and E-vectors calculated from 3-to-8-day band-pass filtered 200hPa wind (arrows; see lower right for scale, in units of $\mathrm{m}^{2} \mathrm{~s}^{-2}$ ) and (b) $850 \mathrm{hPa}$ meridional heat transport $\left(\overline{T^{*} v^{*}}\right)$ (shading; units: $\left.\mathrm{K} \mathrm{ms}^{-1}\right)$ and heat flux $\left(\overline{T^{*} v^{*}}, \overline{T^{*} u^{*}}\right)$ (arrows; see lower right for scale, in units of $\mathrm{K} \mathrm{ms}^{-1}$ ). 
(a) CTRL
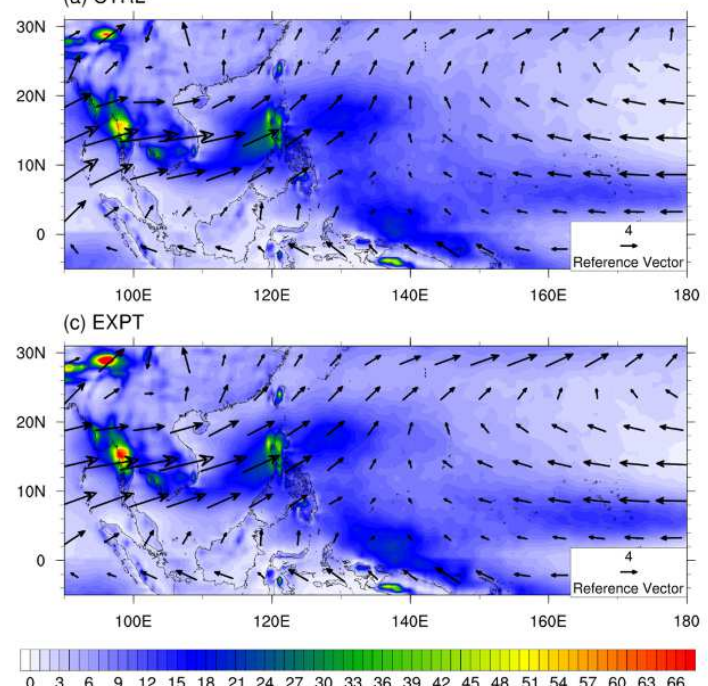

(e) CTRL-EXPT

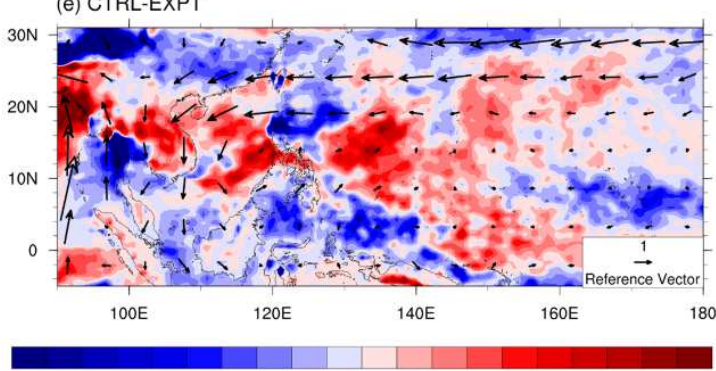

$\begin{array}{llllllllllllllllllll}-4.5 & -4 & -3.5 & -3 & -2.5 & -2 & -1.5 & -1 & -0.5 & 0 & 0.5 & 1 & 1.5 & 2 & 2.5 & 3 & 3.5 & 4 & 4.5\end{array}$ (b) CTRL

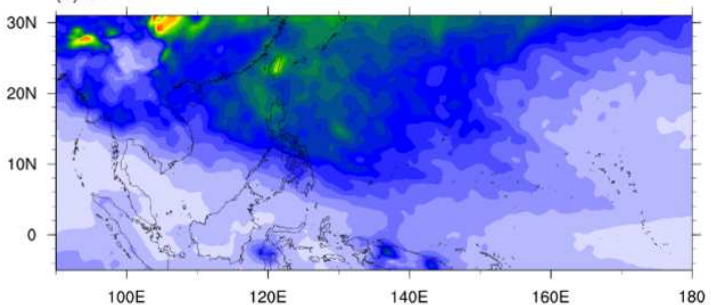

(d) EXPT
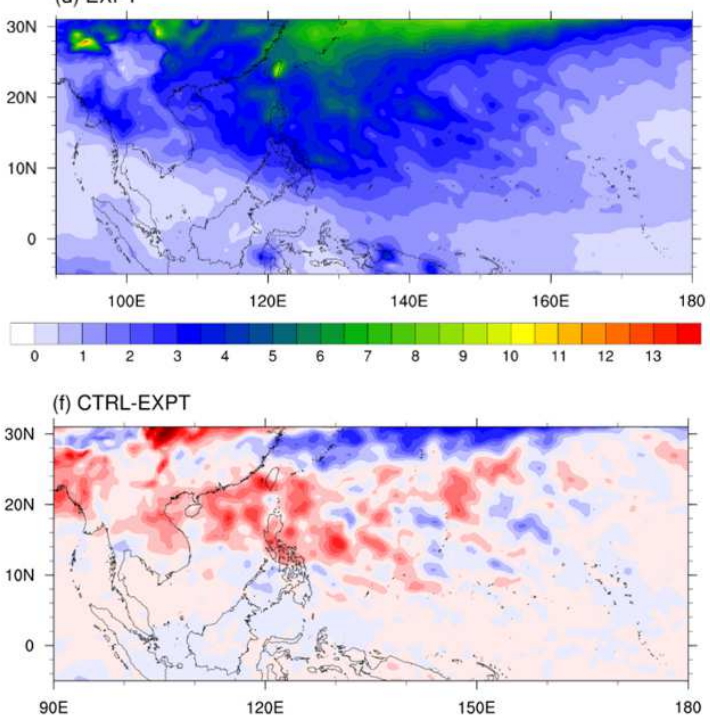

Figure 3. (a, c, e) JJA mean precipitation (shading; units: $\mathrm{mm} /$ day), $850 \mathrm{hPa}$ wind (arrows; see lower right for scale, in units of $\left.\mathrm{ms}^{-1}\right)$ and $(\mathrm{b}, \mathrm{d}, \mathrm{f}$ ) variance of 3-to-8-day band-pass filtered vorticity (units: $10^{-10} \mathrm{~s}^{-2}$ ) for (a, b) CTRL, (c, d) EXPT and (e, f) CTRL minus EXPT. 

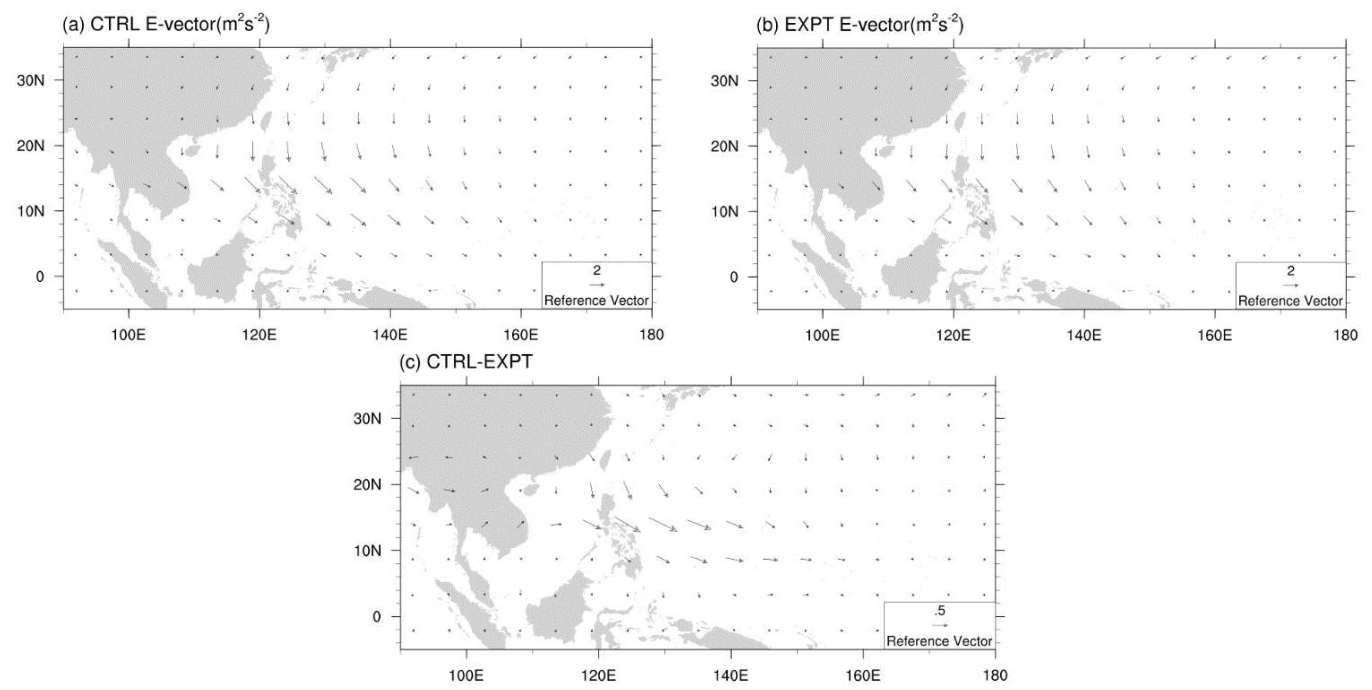

Figure 4. E-vectors calculated from westward propagating $(-20 \leqslant \mathrm{k} \leqslant-4)$ and 3-to8-day band-pass filtered 850hPa wind for (a) CTRL, (b) EXPT and (c) CTRL minus EXPT (see lower right for scale, in units of $\mathrm{m}^{2} \mathrm{~s}^{-2}$ ). 

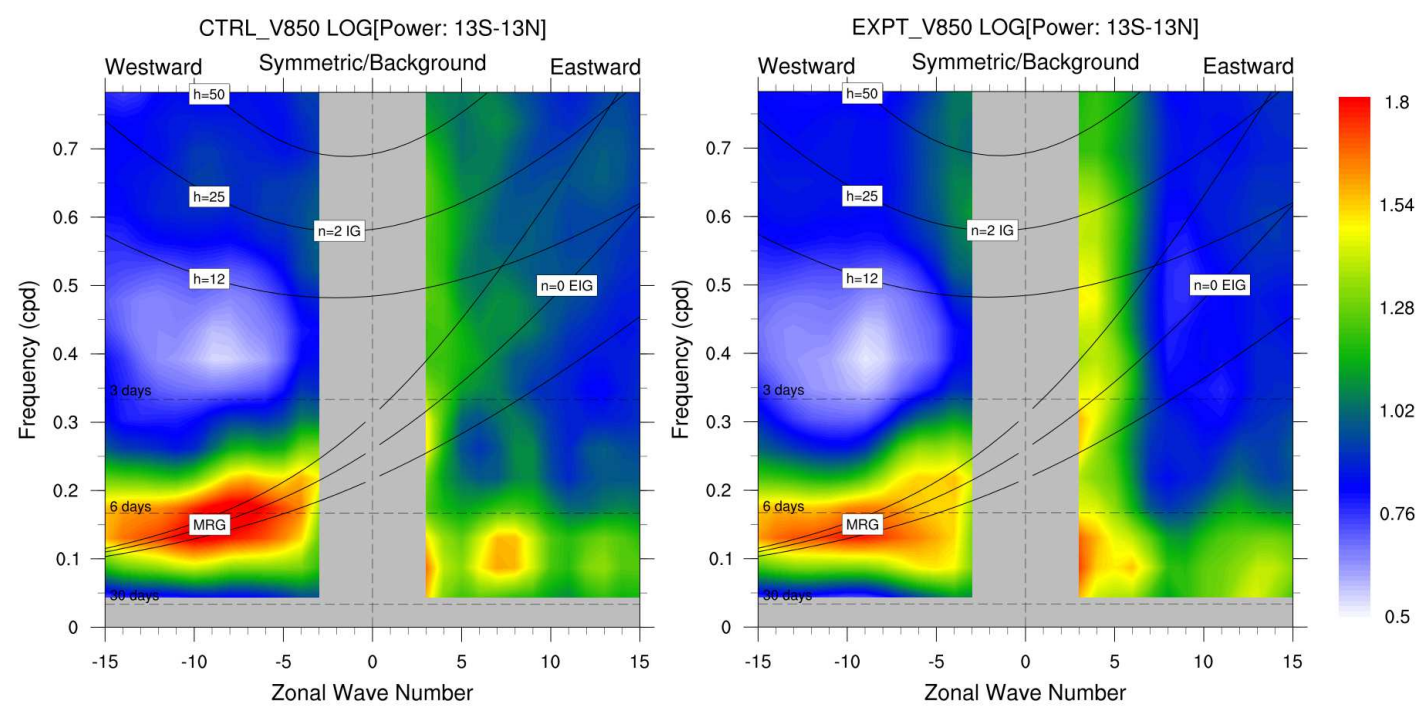

Figure 5. Space-time spectrum of the symmetric component of the $850 \mathrm{hPa}$ meridional wind averaged over $13^{\circ} \mathrm{S}$ to $13^{\circ} \mathrm{N}$ for (a) CTRL and (b) EXPT. Spectra for $|\mathrm{k}|<3$ are not computed due to longitudinal boundaries of the experiments $\left(80^{\circ} \mathrm{E}-160^{\circ} \mathrm{W}\right)$. 

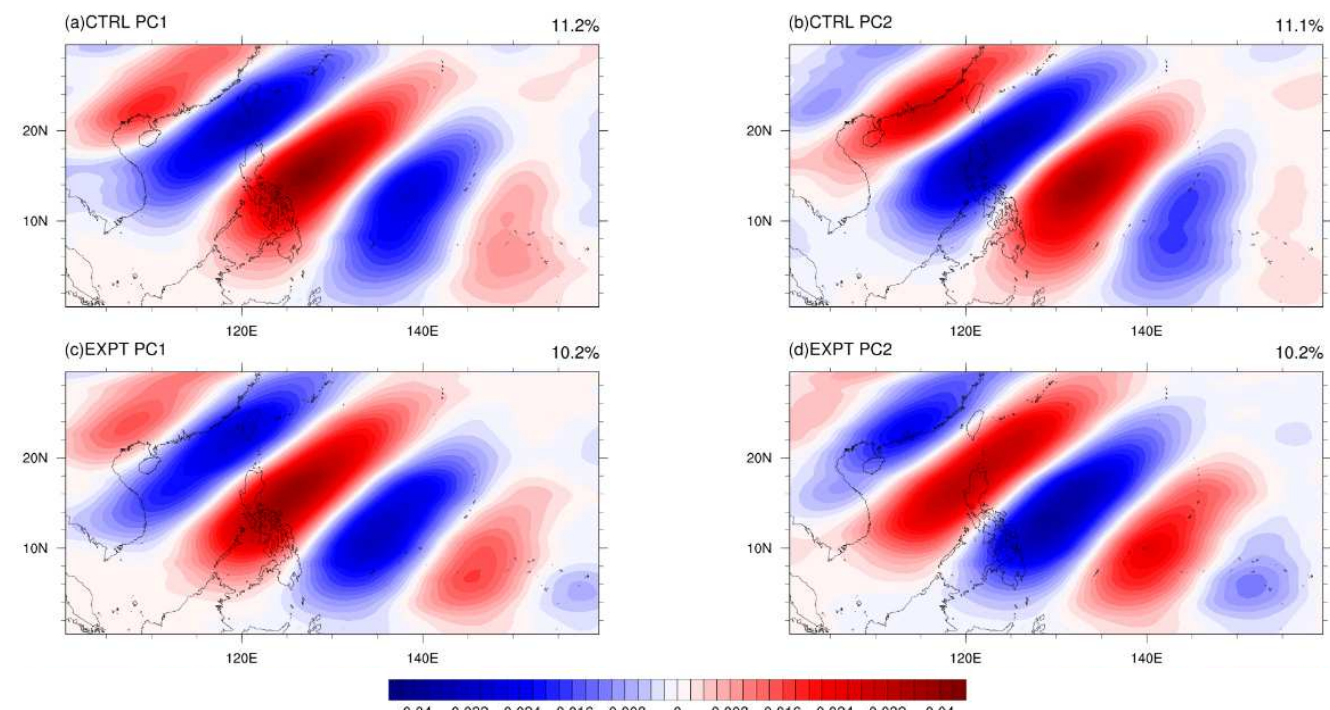

Figure 6. Standardized patterns of $(a, c)$ the first and $(b, d)$ the second leading EOFs of spatially and temporally filtered $850 \mathrm{hPa}$ vorticity over $0-30^{\circ} \mathrm{N}, 100-160^{\circ} \mathrm{E}$ for $(\mathrm{a}, \mathrm{b})$ CTRL and (c, d) EXPT. The percentage of the total variance explained by each EOF is shown in the top-right. See text for details. 


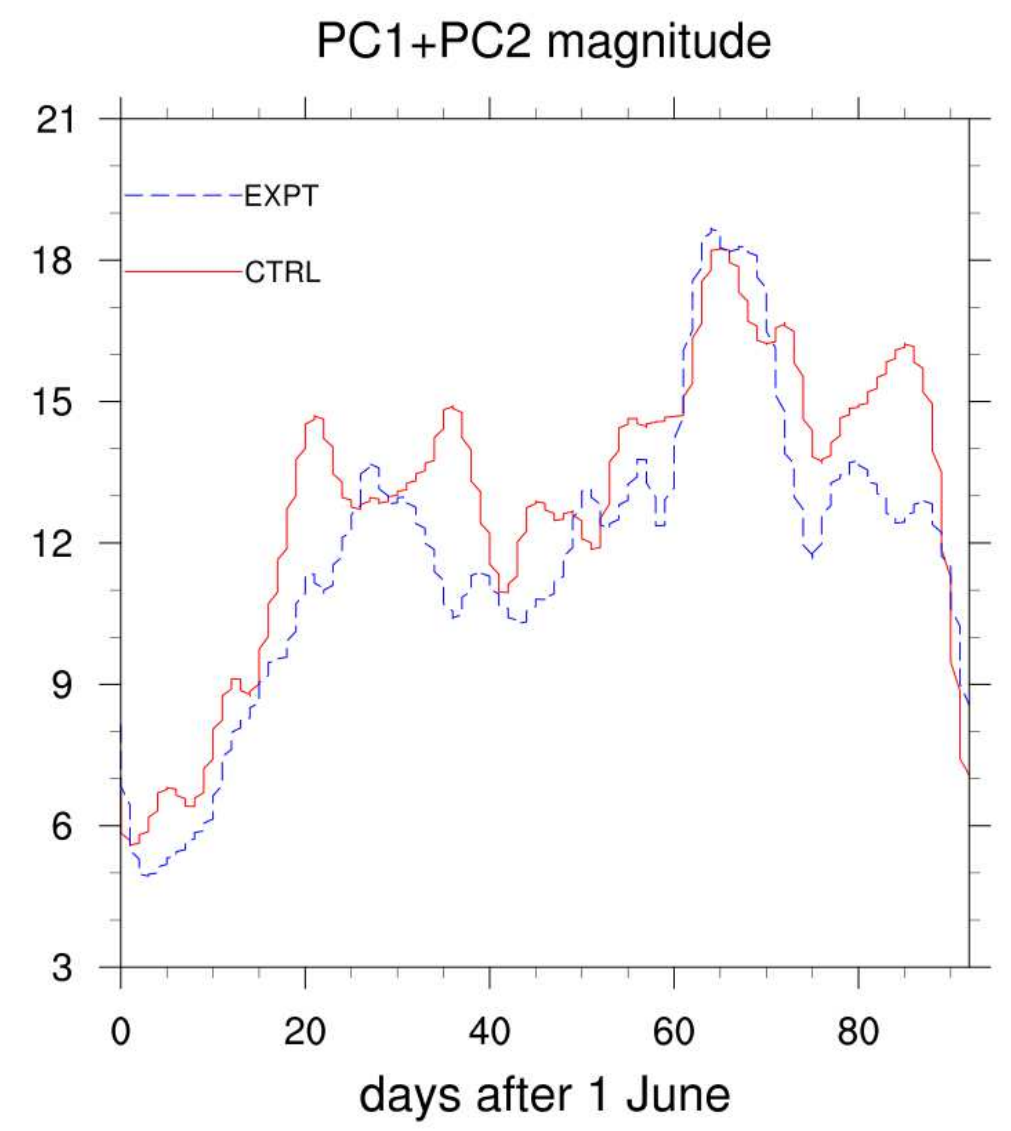

Figure 7. Time-series of the combined magnitude of the two leading EOFs of filtered 850hPa vorticity for CTRL (solid red) and EXPT (dash blue). The value is calculated by $y(t)=\sqrt{P C_{1}(t)^{2}+P C_{2}(t)^{2}}$. See text for details. 


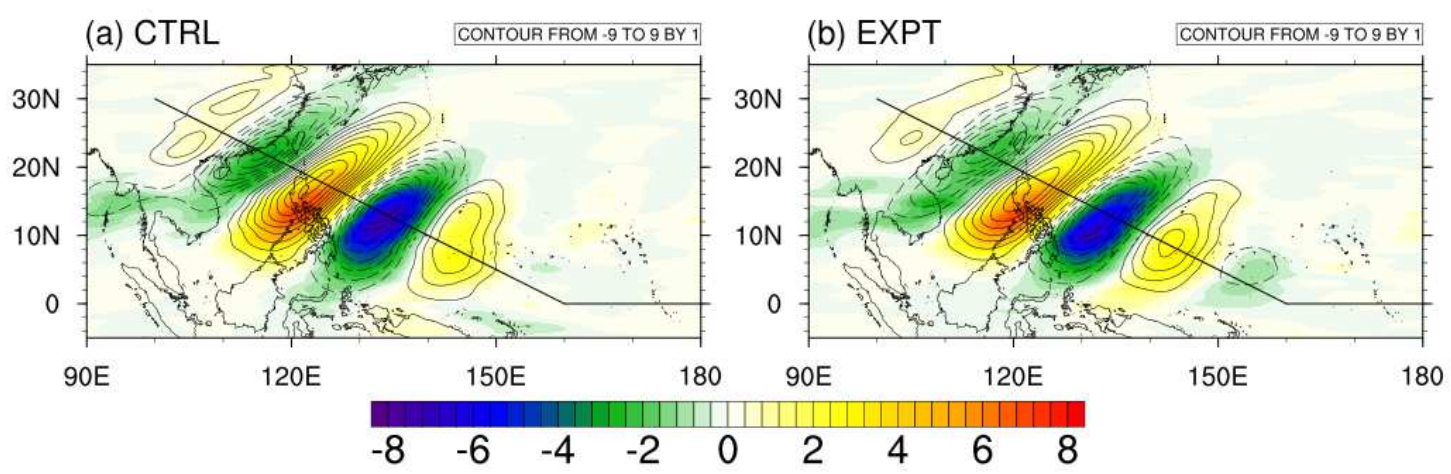

Figure $8.850 \mathrm{hPa}$ vorticity (contours; units: $10^{-6} \mathrm{~s}^{-1}$ ) and precipitation (shading; units:

$\mathrm{mm} /$ day) regressed onto the EOF-filtered $850 \mathrm{hPa}$ vorticity at $15^{\circ} \mathrm{N}, 120^{\circ} \mathrm{E}$ for (a) CTRL and (b) EXPT. Solid and dashed lines represent positive and negative values, respectively. Local maxima of the regressed vorticity signals are joined by the same thick polyline in (a) and (b). 
(a) CTRL

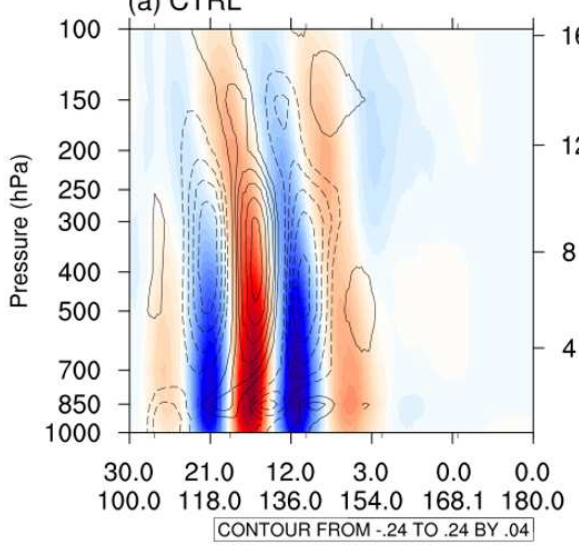

(c) CTRL - EXPT

$\begin{array}{lllllll}-1.5 & -1 & -0.5 & 0 & 0.5 & 1 & 1.5\end{array}$

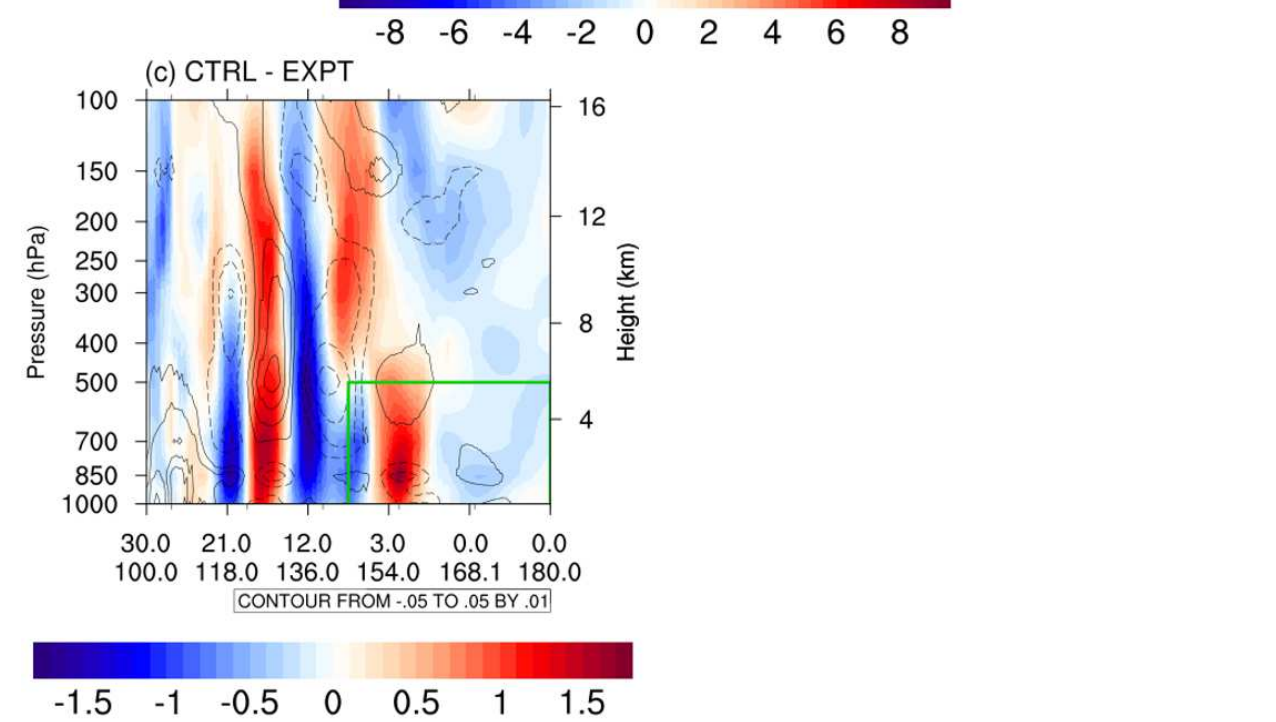

(b) EXPT

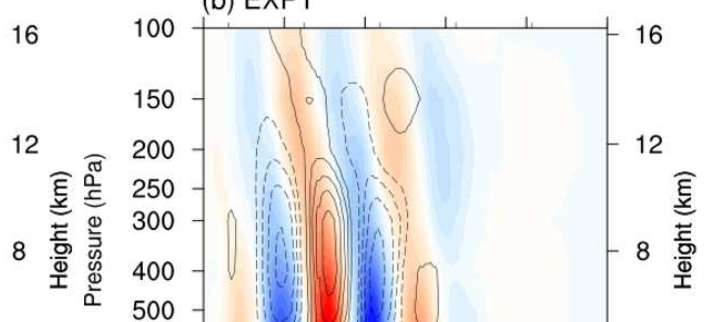

$\begin{array}{llllll}30.0 & 21.0 & 12.0 & 3.0 & 0.0 & 0.0\end{array}$

$\begin{array}{llllll}100.0 & 118.0 & 136.0 & 154.0 & 168.1 & 180.0\end{array}$ CONTOUR FROM -.24 TO $.24 \mathrm{BY} .04$

Figure 9. Vertical cross-section (from $30^{\circ} \mathrm{N}, 100^{\circ} \mathrm{E}$ to $0^{\circ}, 160^{\circ} \mathrm{E}$, then extending to $180^{\circ}$ along the equator; see the black polyline on Fig. 8) of filtered vorticity (shading; units: $10^{-6} \mathrm{~s}^{-1}$ ) and temperature (solid and dashed contours for positive and negative values, respectively, with zero contours omitted; units: K) regressed onto EOF-filtered 850hPa vorticity at $15^{\circ} \mathrm{N}, 120^{\circ} \mathrm{E}$ for (a) CTRL, (b) EXPT, and (c) CTRL minus EXPT. Solid and dashed lines represent positive and negative values, respectively. The green box in (c) indicates the more eastern locations where vorticity signals from EXPT are stronger than CTRL. 
(a) CTRL

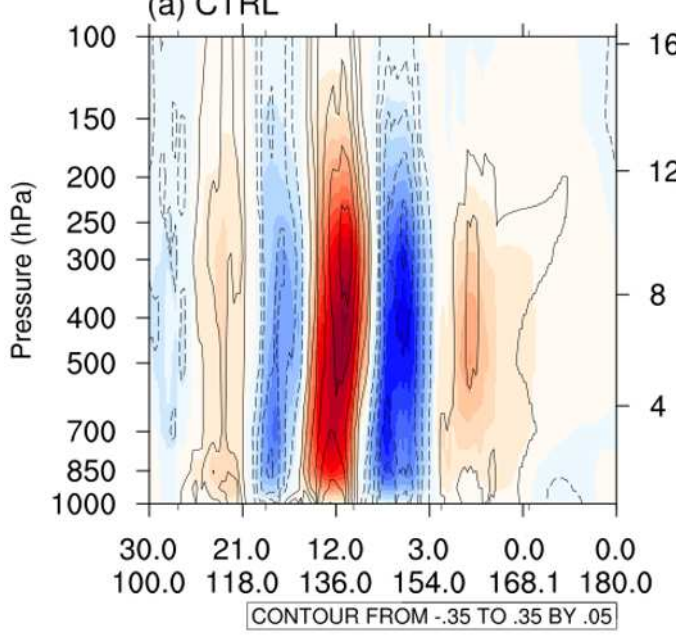

(b) EXPT

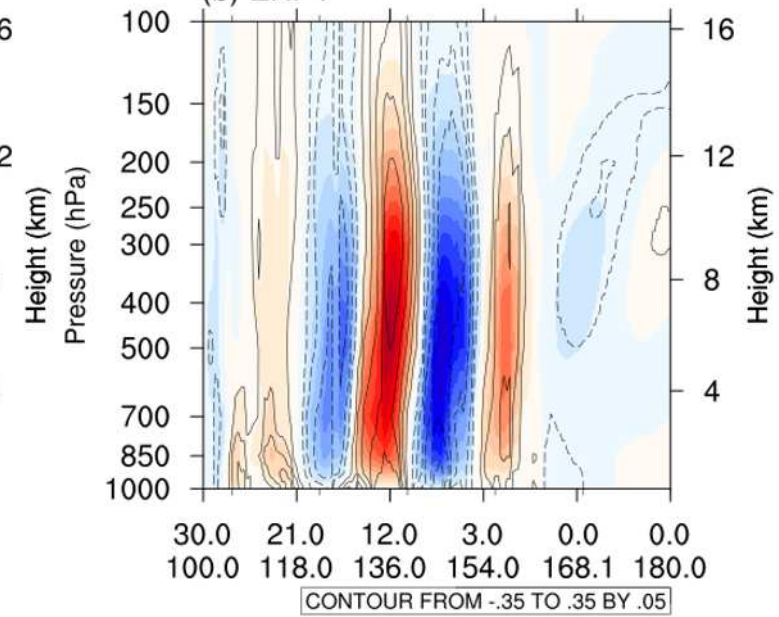

CONTOUR FROM -.35 TO .35 BY .05

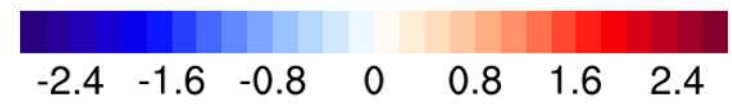

(c) CTRL - EXPT

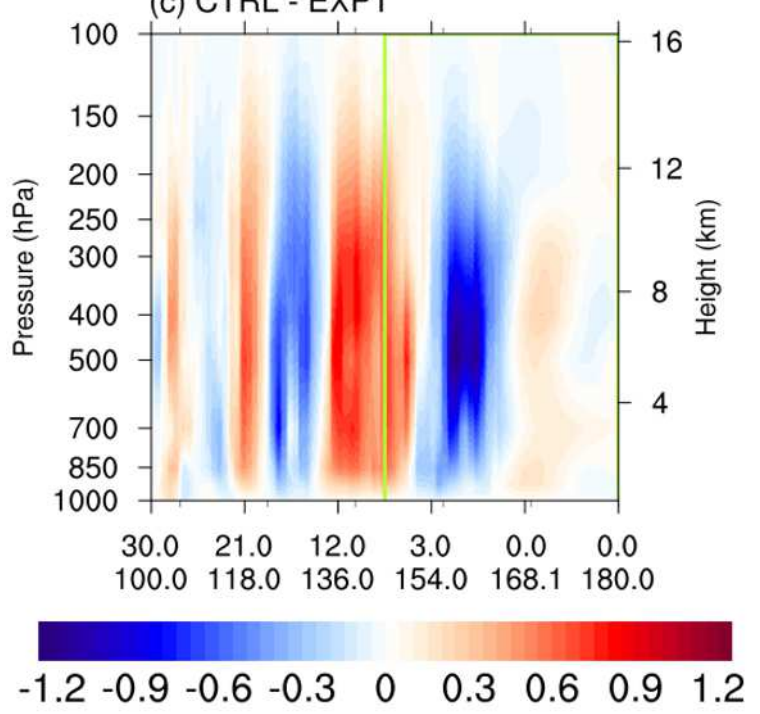

Figure 10. Same as Figure 9, except for the pressure velocity (shading; units: $10^{-5} \mathrm{~Pa} \mathrm{~s}^{-}$

${ }^{1}$, downward as positive) and its correlation with EOF-filtered $850 \mathrm{hPa}$ vorticity at $15^{\circ} \mathrm{N}$,

$120^{\circ} \mathrm{E}$ (contour). The green box in (c) indicates the region where anomalous vertical motion from EXPT is stronger than CTRL 


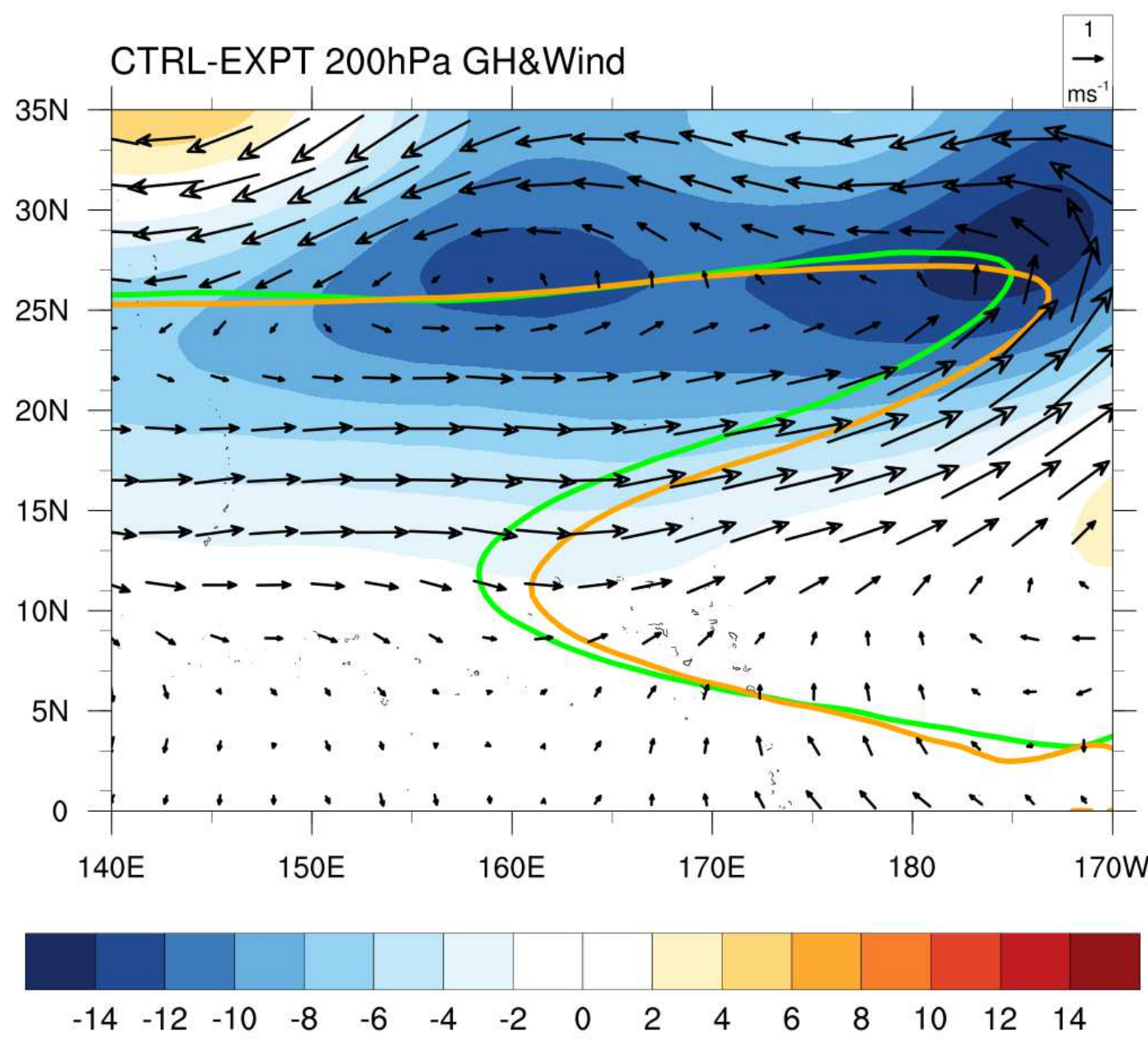

Figure 11. CTRL minus EXPT JJA mean 200hPa geopotential height (shading; unit: m) and wind (arrows; see upper left for scale). Green (orange) solid line indicates the zero line of 200hPa zonal wind in CTRL (EXPT). 
(a) Total difference

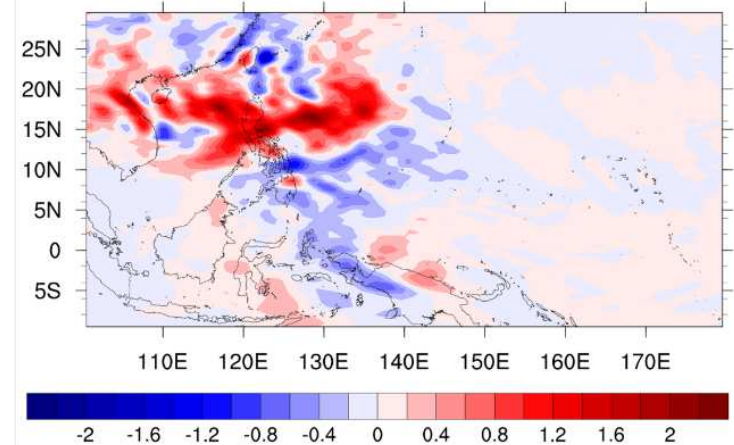

(b) due to background wind

(c) due to eddies
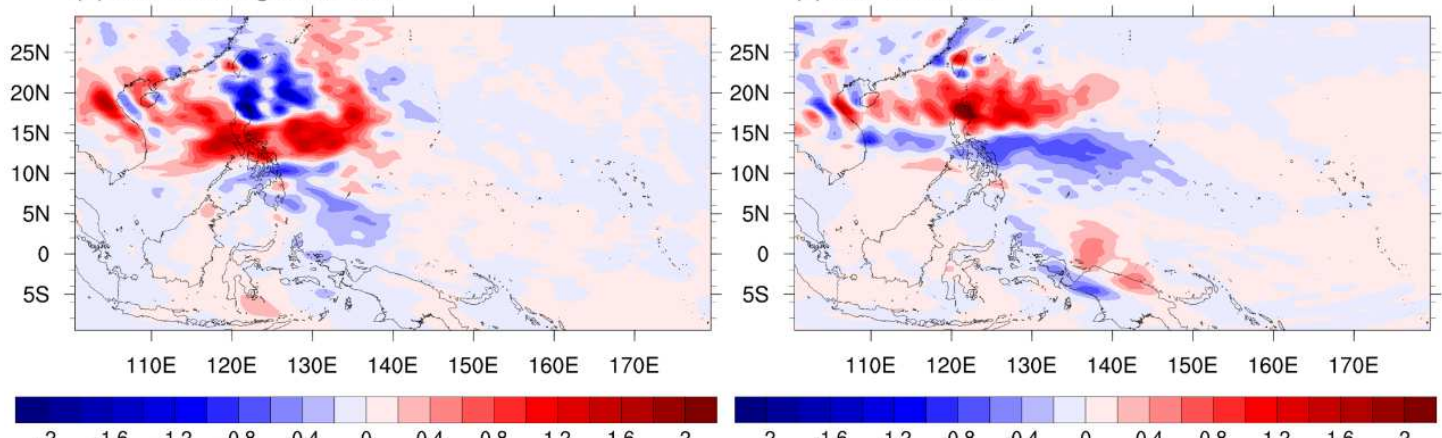

$\begin{array}{llllllllll}-2 & -1.6 & -1.2 & -0.8 & -0.4 & 0 & 0.4 & 0.8 & 1.2 & 1.6\end{array}$

$\begin{array}{lllllllllll}-2 & -1.6 & -1.2 & -0.8 & -0.4 & 0 & 0.4 & 0.8 & 1.2 & 1.6 & 2\end{array}$

Figure 12. (a) Difference in $850 \mathrm{hPa}$ barotropic energy conversion rate associated with EOF-filtered $850 \mathrm{hPa}$ vorticity at $15^{\circ} \mathrm{N}, 120^{\circ} \mathrm{E}(\mathrm{lag}-8$ to +8$)\left(\right.$ units: $10^{-6} \mathrm{~m}^{2} \mathrm{~s}^{-3}$ ) between CTRL and EXPT, and the corresponding difference due to changes in (b) background wind and (c) eddy activities. See text for details. 


\begin{tabular}{lll}
\hline & CTRL & EXPT \\
\hline eastern, western and & wavenumber $=0-6$ climatology & wavenumber $=0-6$ climatology \\
southern boundaries & & \\
\hline northern boundary & wavenumber $=0-6$ climatology + & wavenumber $=0$-6 climatology + \\
& wavenumber $>\mathbf{6}$ transients & $\underline{\mathbf{1 0 \%} \text { of } \text { wavenumber }>\mathbf{6} \text { transients }}$ \\
\hline sea surface & climatological SST & climatological SST \\
temperature & & \\
\hline number of simulations & $\mathbf{7}$ years $\times$ 5-member ensemble & 7 years $\times$ 5-member ensemble \\
\hline
\end{tabular}

Table 1 - Settings of the atmospheric model experiments. The only difference between

CTRL and EXPT experiments lies in the magnitudes of wavenumber $>6$ transients imposed at the northern boundary. See text for details. 